\title{
CHITOSAN AND PECTATE BIOPARTICLES MADE FROM ORANGE ALBEDO. ADSORPTION OF COPPER (II)
}

\author{
BORIS ULLOA ${ }^{a}$, ERIKA TAPIA ${ }^{a}$, MAURICIO ARIAS $^{b}$ AND YASNA LEÓN ${ }^{a *}$ \\ ${ }^{a}$ Departamento de Ciencias Básicas, Universidad Santo Tomás. Chile. \\ ${ }^{b}$ Departamento de Física, Universidad Católica del Norte. Av. Angamos 610, Antofagasta, Chile.
}

\begin{abstract}
The investigation herein reports on the development of bioparticles by mixing calcium pectate with chitosan in order to chelate $\mathrm{Cu}^{+2}$ from water polluted with heavy metals. Calcium pectate was used to synthesize these bioparticles. The pectate was obtained from orange albedo, which was in turn obtained from shredded and dry biomass, treated with an acidulated solution in order to eliminate the pectin (Ps). The first treatment given to the biomass was with a sodium hydroxide solution $(\mathrm{NaOH})$, in order to de-methoxylate the pectin. Subsequently, the biomass was treated with ethyl alcohol and calcium hydroxide $\left(\mathrm{Ca}(\mathrm{OH})_{2}\right)$ to a temperature of $80-90^{\circ} \mathrm{C}$, to renew the pectin. This improved the mechanical stability that this constituent requires. Experimental results of the $\mathrm{Cu}^{+2}$ ions are expressed as a withholding rate percentage in time.
\end{abstract}

Keywords: Chitosan, pectate bioparticles, SEM.

\section{INTRODUCTION}

Industrial activities as mining and textile are highly pollutants to the environment and human health. River and lake pollution by heavy metals is particularly dangerous [1]. When heavy metals as $\mathrm{Cu}(\mathrm{II}), \mathrm{As}(\mathrm{II})$, and $\mathrm{Pb}(\mathrm{II})$, are present in drinking-water sources, even in low concentrations, they can be extremely harmful to the population.

Removal of these metals from polluted water can be achieved by chemical methods of water treatment [2-3]. Although these chemical methods are effective and specific, its application at industrial level is expensive and difficult to put into practice, which has discouraged its use by polluting industries.

A modern alternative to collect these heavy metals is bioremediation; method by which pollutants are captured by means of plants, microorganisms, or their components. Bioremediation has the advantage of being as effective as the other chemical methods, but at a much lower operational cost [4]. Among these methods of bioremediation with heavy metals, the use of chitosan (QS) and pectin (PS) has been particularly interesting, as they are by-products of the food industry with no commercial value that can be reused for pollutants adsorption [5-8].

Calcium pectate (PS) is a vegetal biopolymer found in cell wall and acts as "biologic glue" that keeps cells firm and united; whereas chitosan is a polymer obtained by the N-deacetylation of chitin, a biopolymer found in the exoskeleton of invertebrates, which grants rigidity and mechanical resistance. The fact that chitosan has a high density of free amino and hydroxyl groups makes it a highly versatile material for chemical applications, as it is prone to a wide variety of modifications, such as graft reactions, graft reactions, enzyme anchoring, film cross-linking, and adsorption of metallic impurities [9-10].

In order to transform calcium pectate into a bio adsorbent, it can be intertwined with chitosan, which is also a biopolymer. Hence, reaching better stability of the polymer composite and its particles. Thus, a useful biopolymer to attain heavy metal adsorption, in this case $\mathrm{Cu}^{+2}$, is obtained [11-12].

The coordinate covalent bonds established between calcium and pectin involve the carboxyl and hydroxyl groups of the biopolymer, which allows to form a structure called "egg housing", Fig. 1 [13].

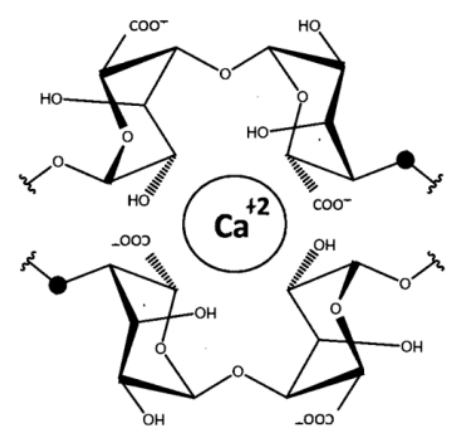

Figure 1. Calcium pectate (II). The diagram depicts the coordinate covalent bonds established between $\mathrm{Ca}^{+2}$ and the carboxyl and hydroxyl groups of 5 D-galacturonic acid monomers.
The objective of the investigation herein was to develop chitosan and calcium pectate spheres in order to chelate $\mathrm{Cu}^{+2}$ and observe their adsorption effects by analyzing the composition of $\mathrm{MgCl}_{2}, \mathrm{CaCl}_{2}$ and Pectate-Chitosan (Ps-Qs) crosslinking areas, which in turn will improve $\mathrm{Cu}^{+2}$ adsorption. Cupper adsorption is expressed as a percentage of retention with respect to the contact time with the spheres.

\section{EXPERIMENTS}

\section{Pectin Extraction from Albedo}

Pectin was obtained from orange albedo (Citrus sinensis), "Valencia" variety [13]. For this purpose, the albedo (white spongy part that comprises the orange's mesocarp) was carefully detached from the orange peel using a knife. Albedo mass per unit of fruit was registered and it was cut into small pieces. The albedo was weighed and then placed in a beaker. Consequently, $300 \mathrm{~mL}$ of distilled water were added to the baker to a temperature of $60^{\circ} \mathrm{C}$ for 15 minutes.

The second stage comprised the albedo hydrolysis, which was performed by means of chemical processes based on exposure to $\mathrm{NaOH}$ and $\mathrm{HCl}$ aqueous solutions. After the first stage, the albedo was treated with sodium hydroxide, which allowed for pectin methylation. Then, hydrochloric acid was added to make the solution have a $\mathrm{pH}$ of 2-3 to continue hydrolyzing to a temperature of $70{ }^{\circ} \mathrm{C}$ for one hour.

Temperature was controlled during all the process in order to accomplish an adequate extraction, as temperature is not critical for the denaturation of the aforementioned component required for this investigation.

Once the $\mathrm{pH}$ was adjusted, the solution was periodically shaken to ensure the orange albedo's complete degradation, and to improve the extraction performance.

$300 \mathrm{~mL}$ of boiling water were added to the pectin residue, to be subsequently shaken and removed. Then, $300 \mathrm{~mL}$ of ethyl alcohol were added and the mixture was left to settle for 2 hours, until pectin precipitation was achieved.

The precipitate was filtered and the solution obtained was maintained for the precipitation process of the calcium pectate.

\section{Calcium Pectate Precipitation (PS)}

The pectin obtained in the previous stage was acidified with $\mathrm{HCl}$ to then reach $\mathrm{pH} 4$ by constant stirring. Subsequently, a drip solution of $\mathrm{Ca}(\mathrm{OH})_{2}$ to $5 \% \mathrm{~m} / \mathrm{v}$ was added until both a transparent solution and calcium pectate precipitation were achieved. The precipitate was vacuum filtered, washed with ethanol, and acidified to release excess calcium. Then, it was washed again with ethanol and was left to dry.

\section{Pectate-Chitosan (Ps-Qs) Spheres Formation}

$2 \mathrm{~g}$ of Ps were dissolved in $400 \mathrm{~mL}$ of $4 \%$ acetic acid $\mathrm{m} / \mathrm{v}$, with agitation at $350 \mathrm{rpm}$. Next, $2 \mathrm{~g}$ of Qs (provided by Quitoquímica Chile, with 92\% deacetylation and molecular weight of $178000 \mathrm{~g} / \mathrm{mol}$ ) were slowly added and kept under constant agitation during 24 hours, in order to achieve an adequate homogenization at room temperature. 
In order to produce the Pectate-Chitosan spheres, $4 \mathrm{~mL}$ of Ps-Qs solution were placed on a beaker, with agitation at $100 \mathrm{rpm}$. Then, a $2 \% \mathrm{~m} / \mathrm{v}$ methanol-NaOH drip solution, in a 2:5 ratio, was added, thus forming the spheres. Similarly, QsPs spheres were obtained from a reaction with magnesium chloride and calcium chloride: $4 \mathrm{~mL}$ of Ps-Qs solution with $1 \mathrm{~g}$ of salt $\left(\mathrm{MgCl}_{2}\right.$ y $\left.\mathrm{CaCl}_{2}\right)$ and subsequent mix with a methanol-NaOH mixture.

Then, the spheres were washed with deionized water and a $2.5 \% \mathrm{w} / \mathrm{v}$ solution of glutaraldehyde was added to then left it to stand for 12 hours.

\section{Cu Adsorption by QS-PS Bioparticles}

One of the processes for the adsorption of metallic ions is through columns packed with resins in the inside. The investigation herein worked with two different contact techniques between the biospheres (sorbent) and the metallic ion (sorbate). The first technique was a recirculation system; the tests were performed in $1.1 \mathrm{~cm}$ wide and $30 \mathrm{~cm}$ long columns by which the solutions were eluted. This was accomplished by using a peristaltic pump for a constant elution of the analyte, thus monitoring the time of contact of the sorbent with the sorbate. An aliquot of $20 \mathrm{~mL}$ was taken with an initial flow of $2 \mathrm{~mL}$ per minute.

The second technique was a stationary phase consisting of a battery of test tubes with samples of different biospheres, which are submerged in a $10 \mathrm{~mL}$ analyte solution, and were left to stand for 22,44 and 68 hour intervals. In both techniques, 100 ppm copper standard solution was used.

\section{SEM-EDS Analysis}

Scanning Electron Microscopy-X-ray energy scattering spectrometry (SEMEDS) in the ETEC Autoscan JEOL-JEM 1200 EX II equipment is used. The morphology is determined and the analysis of the elements is carried out in several previously selected points.

\section{FT-IR studies}

Fourier Transform Infrared Spectroscopy (FT-IR) was employed in the Nicolet Change 330 equipment, which is a PC-connected device with OMNIC analysis software for the superficial characterization of particles through the functional groups presented by chitosan.

\section{Atomic Absorption Spectroscopy}

The copper concentration of the collected solutions was determined by atomic absorption spectroscopy, Analytik Jena ContraAA 300 model, at a wavelength of $325 \mathrm{~nm}$.

The adsorption results are expressed in percentage of analyte retention with respect to the contact time for the different systems used in this research.

\section{RESULTS AND DISCUSSION}

The infrared spectra obtained for the spheres allowed us to perform a qualitative characterization of the chemical structure present in the different synthesized compounds. The FT-IR spectrum of Chitosan (Fig. 2) shows the characteristic bands of the biopolymer: $v(\mathrm{~N}-\mathrm{H})$ and $v(\mathrm{OH})$ at $3419 \mathrm{~cm}^{-1}$; amide band carbonyls $(\mathrm{vC}=\mathrm{O})$ at $1647 \mathrm{~cm}^{-1}$ in the middle; $\delta \mathrm{N}-\mathrm{H}$ belts at 1567 and $1411 \mathrm{~cm}^{-1}$; and the band at $1071 \mathrm{~cm}^{-1}$ were assigned to the vibration $v(\mathrm{C}-\mathrm{O})$ [14].

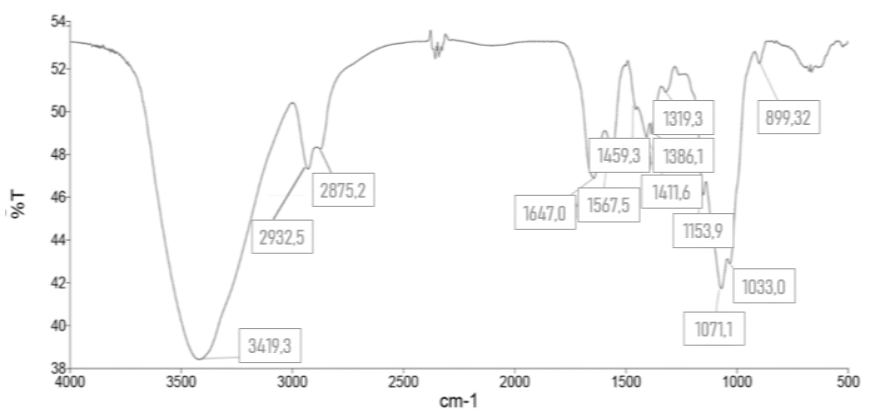

Figure 2. Chitosan FT-IR Spectrum.

The FT-IR pectate spectra show a strong and wide absorption at 3420-3450 $\mathrm{cm}^{-1}$, corresponding to the stretching vibrations of the $-\mathrm{OH}$. In addition, an intense band assigned to $1430 \mathrm{~cm}^{-1}$ carboxylate $(\mathrm{vCOO})$ is observed (Fig. 3), which is week in spectrum 4 and 5 . The former band may be assigned to the asymmetric stretching vibration of the $(\mathrm{vCOO})$ and the latter to the symmetric stretching (vCOO ) [15].

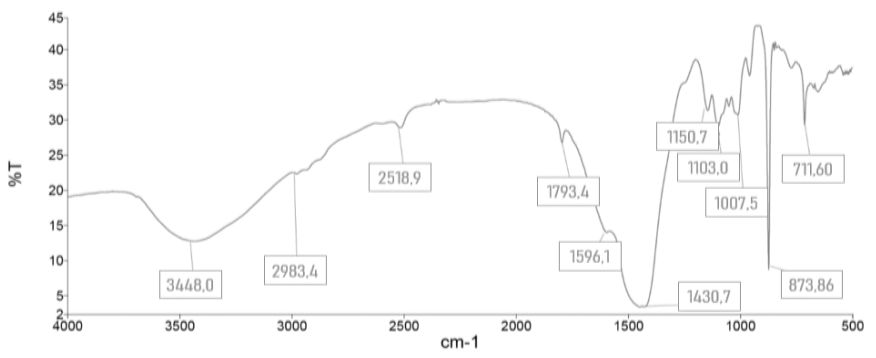

Figure 3. Pectate FT-IR Spectrum.

On the other hand, chitosan-calcium pectate and calcium pectate show a strong peak at $1074-1013 \mathrm{~cm}^{-1}$, respectively, assigned to the symmetrical group stretching vibration (COC). (Fig. 4-5). The -COO- symmetric stretching vibration absorption peak appeared at $1402 \mathrm{~cm}^{-1}$, indicating that pectin and chitosan have polymerization reaction. This result is consistent with literature and reports[16].

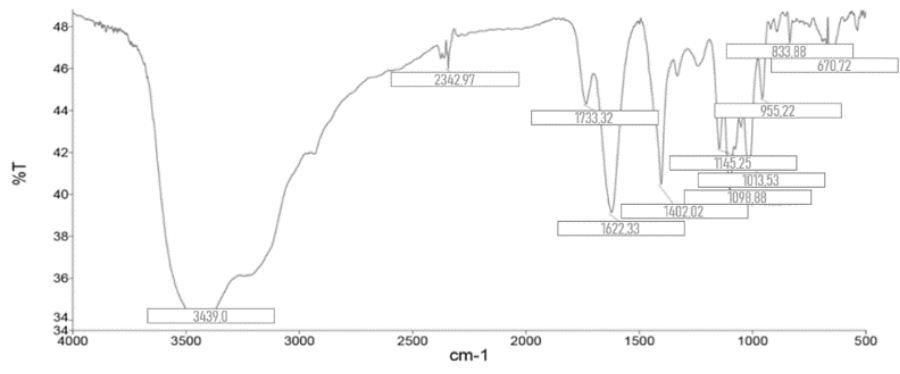

Figure 4. Chitosan-Calcium Pectate FT-IR Spectrum.

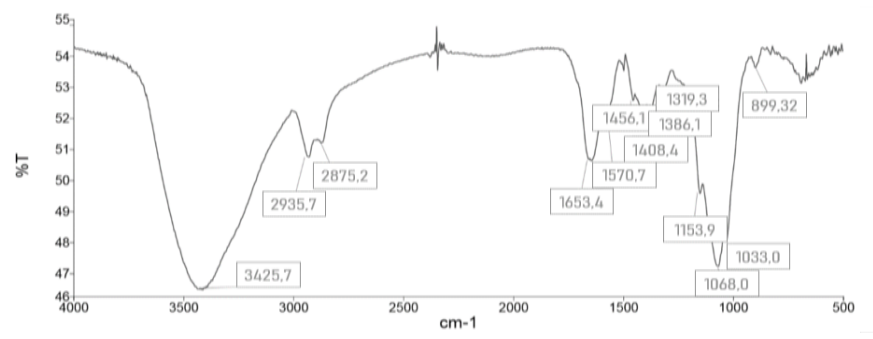

Figure 5. Calcium Pectate FT-IR Spectrum.

The spectrum band observed at $2.940-2.980 \mathrm{~cm}^{-1}$ corresponds to the tension of the $\mathrm{CH}_{2}-\mathrm{CH}$ groups. In addition to the bands observed at $1,500-1,650 \mathrm{~cm}^{-1}$ corresponding to the carbonyl groups of the biopolymer.

The SEM micrograph of the chitosan sphere pectate before elusion shows some heterogeneous channels without the granular and rough surface (Fig. 6). The porosity structure of the Chitosan-Pectate beads contributes to the cell adherence and proliferation [17]. Part of this effect could be due rehydration, in fact, gel rehydrated only with water still presented a less uniform structure [18].

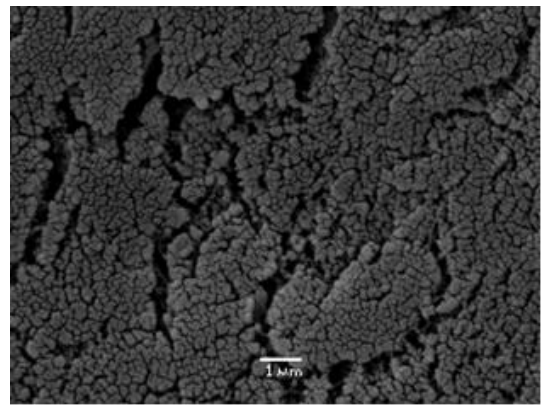

Figure 6. SEM micrograph of the Chitosan spheres pectate. 
The SEM micrograph of the chitosan sphere pectate after copper elution shows a chitosan surface more compact than the pectate (Fig. 7). EDS energy dispersive spectrometry showed the presence of copper on the surface of the biopolymer.
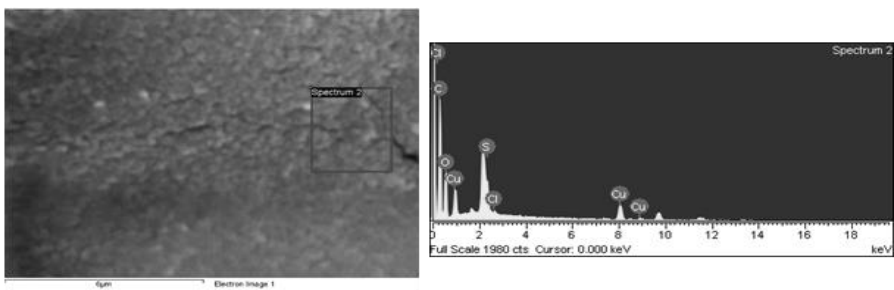

Figure 7. SEM micrograph of the Chitosan-Pectate sample, after elution with copper solution.

SEM micrograph of calcium pectate-Chitosan samples shows a carcass surface and fibrous texture of heterogeneous sizes. The EDS evidences the characteristic peaks of the main component of the compound, showing $\mathrm{C}, \mathrm{O}$, and $\mathrm{Ca}$ (Fig. 8). Additionally, copper peaks are observed after completion of the elution.
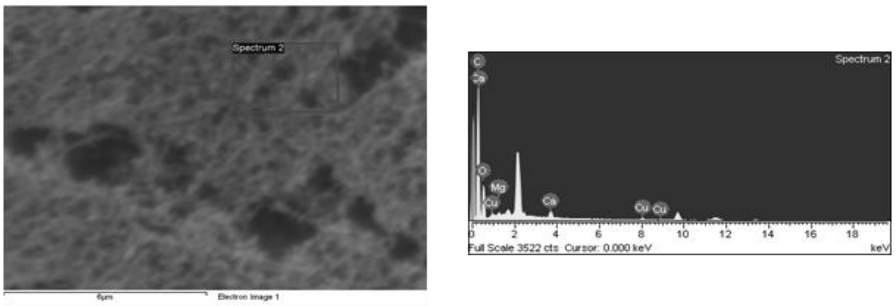

Figure 8. SEM and EDS micrographs of the Calcium-Chitosan Pectate spheres, after elution with copper solution.

The morphology of the surface of the sphere of the magnesium chitosanpectate biopolymer by SEM analysis shows a very rough and laminated surface in the surface areas associated with the presence of magnesium adhered to the surface of the polymeric matrix (Fig. 9). The EDS analysis corroborates the presence of magnesium and copper in the biopolymer.
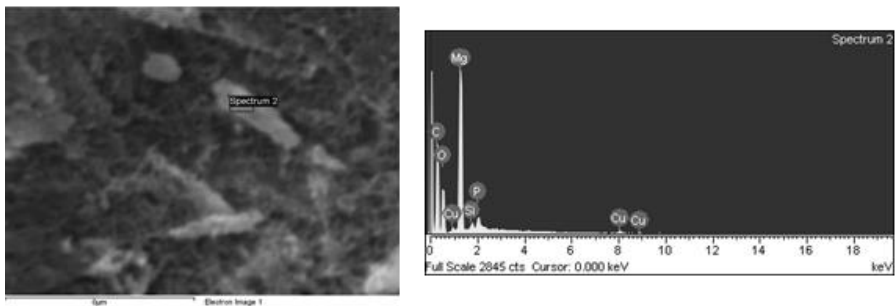

Figure 9. SEM and EDS micrograph of the Chitosan-Pectate, after elution with copper and magnesium solution.

The morphological difference can be attributed to the difference cross-linking degree due to the variability of the number and position of functional groups [19]. The influence of these two parameters on size, shape and morphology has been discussed by Smrdel et al [20].

\section{Determination of Ps-Qs spheres capacity}

Tables 1-4 depict some final concentrations of the systems with the best $\mathrm{Cu}^{+2}$ adsorption capacity.

\begin{tabular}{|c|c|c|c|}
\cline { 2 - 4 } \multicolumn{1}{c|}{} & \multicolumn{3}{c|}{ HOURS } \\
\hline Stationary phase & $\mathbf{2 2}$ & $\mathbf{4 4}$ & $\mathbf{6 8}$ \\
\hline $\mathrm{CaCl}_{2} \quad 1: 1$ & 22.88 & 5.4 & 4.69 \\
\hline $\mathrm{MgCl}_{2} \quad 1: 1$ & 11.66 & 2.8 & 3.1 \\
\hline $\mathrm{Mgcl}_{2} \quad 3: 1$ & 15.99 & 3.8 & 1.75 \\
\hline
\end{tabular}

\begin{tabular}{|c|c|c|}
\hline \multicolumn{3}{|c|}{ Final Concentration } \\
\hline $\mathbf{2 2}$ & $\mathbf{4 4}$ & $\mathbf{6 8}$ \\
\hline 77.12 & 94.6 & 95.31 \\
\hline 88.34 & 97.2 & 96.9 \\
\hline 84.01 & 96.2 & 98.25 \\
\hline
\end{tabular}

Tables 1 and 2. Final concentrations of stationary phase adsorption systems.

\begin{tabular}{|c|c|c|c|}
\cline { 2 - 4 } \multicolumn{1}{c|}{} & \multicolumn{3}{c|}{ HOURS } \\
\hline Recirculation & 22 & 44 & 68 \\
\hline Mixed recirculation & 1.9 & 0.97 & 0.99 \\
\hline
\end{tabular}

\begin{tabular}{|c|c|c|}
\hline \multicolumn{3}{|c|}{ Final Concentration } \\
\hline 22 & 44 & 68 \\
\hline 98.1 & 99.03 & 99.01 \\
\hline
\end{tabular}

Tables 3 and 4. Final concentrations of recirculating adsorption systems.

The affinity of $\mathrm{d}$ metals is attributed to their ability to form complexes not only through carboxyl but also through hydroxyl group [21]. The sorption is based on the amount of calcium substitution with ions of d-metals, calcium ions are found in the initial part of the ascending sequence.

$$
\mathrm{Mg}^{+2}<\mathrm{Ca}^{+2}<\mathrm{Ni}^{+2}<\mathrm{Pb}^{+2}<\mathrm{Co}^{+2}<\mathrm{Zn}^{+2}<\mathrm{Cu}^{+2}<\mathrm{Mn}^{+2}[22] .
$$

In the process of Copper (II) absorption, we worked at different $\mathrm{pH}$, being the $\mathrm{pH}=5$ with which the best results were obtained. Figure 10 shows the percentages of retention at different times. All systems, regardless of the technique used, have a high percentage of retention, over $95 \%$.

The exchange between cooper with calcium has also been documented by Dronnet et al during absorption with citrus pectin using potentiometric and spectrophotometric methods [23].

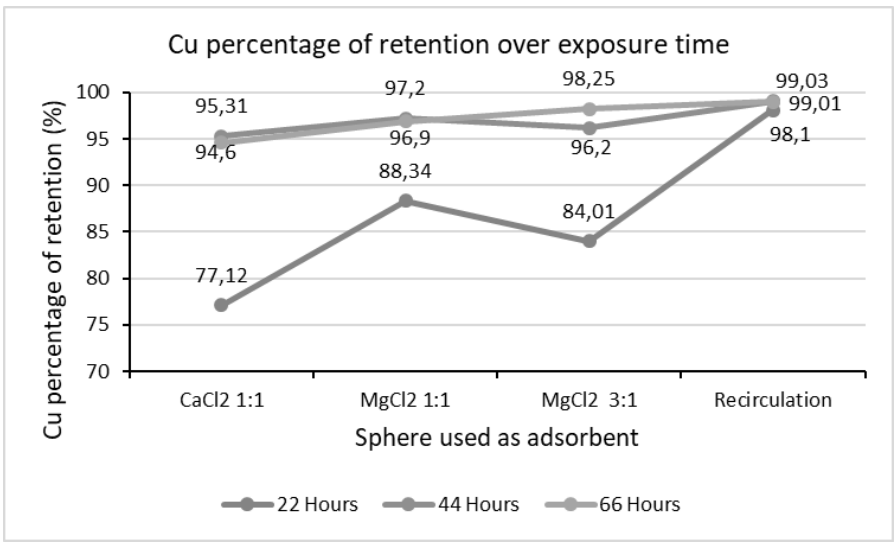

Figure 10. Percentages of retention.

\section{CONCLUSIONS}

Scanning electron micrographs (SEM) show that chitosan-pectate compounds have a regular surface, while the compounds to which calcium and magnesium were added are fibrous.

The EDS energy dispersive spectrometry profiles show that the layers observed in the SEM correspond to Calcium and Magnesium formations, according to the type of counterion used in the Qs-Ps particles.

The FTIR spectra of the chitosan showed characteristic bands of the biopolymer. While in the Chitosan-pectate, calcium pectate, and calcium chitosan-pectate spectra, different signals to those of chitosan by itself were observed. This indicates that there is a cross-linking between both structures.

It was determined that both particles containing calcium and magnesium adsorbed an amount of copper close to $98 \%$, making them highly efficient adsorbents for copper.

\section{ACNOWLEDGEMENTS}

The author would like to thank the financial support of Grant N000012866 Universidad Santo Tomás.

\section{REFERENCES}

1. K. Santhana, et al, Chem. Eng. J. 211, 396 (2012).

2. D. Lalhmunsiama, S. Tiwari, M. Lee, Environ. Eng. Res. 17,41 (2012).

3. S. Lee, D. Lalhmunsiama, S. Tiwari, Chem. Eng. J. 270, 496 (2015).

4. N. Montaño, Revista Internacional de Contaminación Ambiental, 31, 211 (2015).

5. G. Walker, L.Weatherley, Water Research, 31, 2093 (1997).

6. G. Crini, P. Badot, Progress in Polymer Science, 33, 399 (2008).

7. C. Tejada, A. Villabona, L. Garcés, Tecno Lógicas, 18, 109 (2015). 
8. L. Zhou, Y. Wang, Z. Liu, Q. Huang, Journal of Hazardous Materials, 161, 995 (2009).

9. E. Azzam, et al., International Journal of Biological Macromolecules, 89, 507 (2016).

10. Y. Kim, L.Wicker, Advances in Biopolymers, ACS, 935, 230 (2006).

11. Y. Kim, L. Wicker, Food Hydrocolloids, 25, 419 (2011).

12. H. Lee et al., Journal of the Science of Food and Agriculture, 88, 2102 (2008).

13. J. Jung, R. Arnold, L. Wicker. Colloids Surf B Biointerfaces, 104, 116 (2013).

14. Y. León, G. Cárdenas, M. Arias, J. Chim.Chem.Soc, 62, 3661 (2017).

15. P. Castaldi, G. Lauro, C. Senette, S. Deiana, Plant Physiology and Biochemistry, 48, 1008 (2010).

16. G. Morris, M. Kok, S. Harding, G. Adams, Biotechnol. Genet. Eng., 27, 257 (2010).
17. F. Munarin, et al., Biomacromolecules. 12, 568 (2011).

18. Y. Mata, M. Blazquz, A. Ballester, F. González, J. Muñoz, Chemical Engineering Journal, 150, 289, (2009).

19. S. Aleksandrovich, S. Vladimirovna, O. Vladimirovna, Journal of Molecular Liquids, 283, 606 (2019).

20. P. Smrdel, M. Bogataj, A. Mrhar, Sci. Pharm, 76, 77 (2008).

21. B. Gyurcik, L. Nagy, Coord. Chem. Rev, 203, 81 (2000).

22.S. Cataldo, A. Gianguzza, A. Pettignano, I. Villaescusa, Reactive\& Functional Polymers, 73, 207 (2013).

23. V. Dronnet, C.Renard, M. Axelos, J. Thibault, Barbohydr. Polym., 30, 253 (1996). 